\title{
Smart UV Derivative Spectrophotometric Methods for Simultaneous Determination of Metformin and Remogliflozin: Development, Validation and Application to the Formulation
}

\author{
Mahesh Attimarad ${ }^{1, *}$, Anroop Balachandran Nair1, Sreeharsha Nagaraja ${ }^{1,2}$, Bandar Essa Aldhubiab1, \\ Katharigatta Narayanaswamy Venugopala ${ }^{1,3}$, Shinu Pottathil ${ }^{4}$
}

1'Department of Pharmaceutical Sciences, College of Clinical Pharmacy, King Faisal University, Al-Hofuf, Al-Ahsa, KSA. ${ }^{2}$ Department of Pharmaceutics, Vidya Siri College of Pharmacy, Off Sarjapura Road, Bangalore, Karnataka, INDIA. ${ }^{3}$ Department of Biotechnology and Food Technology, Durban University of Technology, Durban, SOUTH AFRICA. ${ }^{4}$ Department of Biomedical Sciences, College of Clinical Pharmacy, King Faisal University, Al-Hofuf, Al-Ahsa, KSA.

\begin{abstract}
Background: The result of pharmaceutical industry research for the new class and the new combination of drugs for the treatments of diabetes is the newly approved combination of metformin (MET) and remogliflozin (REM). For the quality control of this formulation, three smart, reproducible and non-sophisticated spectroscopic techniques were developed by modification of UV spectra. Materials and Methods: The first two methods were based on the measurements of the peak height of the third derivative and second derivative ratio spectra of MET and REM and the third method was the constant center spectrum subtraction method. Results: The proposed methods exhibited Beer's law in the range of 2.5 to $30 \mu \mathrm{g} / \mathrm{ml}$ and 1 to $24 \mu \mathrm{g} / \mathrm{ml}$ for MET and REM correspondingly by all three methods. The mean percentage recovery was found to be in the range of $99.08 \%$ to $100.15 \%$ for MET and $98.73 \%$ to $100.27 \%$ for REM. Further, both analytes were quantified from the formulation using proposed spectroscopic methods with high accuracy. Comparison of all three methods with the reported HPLC method showed no variation in the assay outcomes in relation to accuracy and precision. Conclusion: The suggested techniques are simple, accurate and reproducible, hence could be used for regular quality control of formulation consisting of MET and REM.
\end{abstract}

Key words: Metformin, Remogliflozin, UV, Derivative spectroscopy, Validation, Formulation.

\section{INTRODUCTION}

Metformin $\mathrm{HCl}$, chemically known as 1,1-Dimethylbiguanide hydrochloride (Figure 1A) is extensively used for the management of diabetes mellitus Type-2. It is a first choice for the management of blood glucose due to its multiple mechanisms of action and safety. ${ }^{1-3}$ However, slowly glycemic control reduces hence patients require a higher dose of metformin or additional anti-diabetic drug for reducing the blood glucose level to normal. ${ }^{3}$ Sodium-glucose transport protein (SGLT) inhibitors are recent among the many new class of antidiabetic drugs developed during the past two decades. Inhibition of SGLT rises the elimination of glucose by inhibiting the reabsorption of glucose from the glomerular filtrate. ${ }^{4,5}$ Several SGLT inhibitors such as canagliflozin, empagliflozin dapagliflozin are successfully administered with metformin. ${ }^{6}$ Recently, Food and Drug Administration has approved a combination of remogliflozin etabonate (Figure 1B) and metformin filmcoated tablets in two strengths of $500 \mathrm{mg}$ / 1000 mg MET with 100 mg REM. ${ }^{7}$ REM chemically known as $\beta$-D-Glucopyranoside,
Submission Date: 12-10-2020; Revision Date: 18-01-2021; Accepted Date: 21-02-2021

DOI: 10.5530/ijper.55.1s.62 Correspondence: Dr. Mahesh Attimarad

Department of Pharmaceutical Sciences, College of Clinical Pharmacy, King Faisal University, Al-Hofuf, Al-Ahsa, 31982, KSA.

Phone no:

+966-013-58999601

Email id: mattimarad@kfu. edu.sa

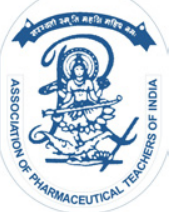

www.ijper.org 


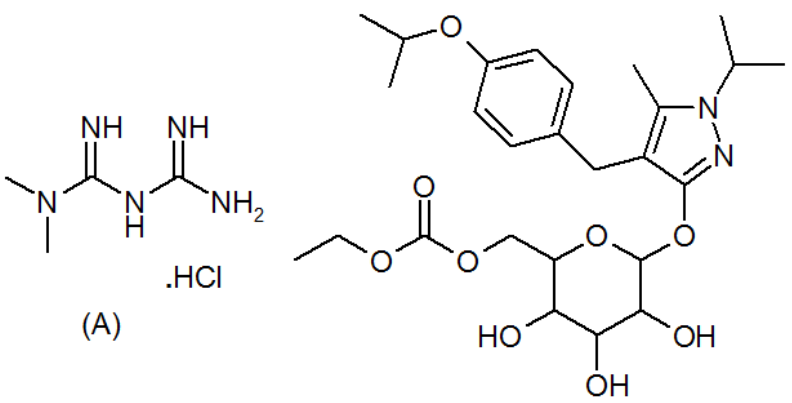

(B)

Figure 1: Chemical Structures of Metformin $\mathrm{HCl}(\mathrm{A})$ and Remogliflozin etabonate (B)

5-methyl-4-[[4-(1-methylethoxy)phenyl]methyl]-1-(1methylethyl)-1H-pyrazol-3-yl, 6-(ethyl carbonate), acts by inhibiting specific enzyme SGLT-2 and is insulinindependent anti-diabetic drug. In addition, REM helps in reducing the body weight and blood pressure in diabetes mellitus patients. ${ }^{8-10}$

Many analytical methods were illustrated for the estimation of MET from pharmaceutical preparations and plasma by spectroscopic, ${ }^{11,12}$ HPLC, ${ }^{13-15}$ HPLTC, ${ }^{16}$ LC-MS, ${ }^{17,18}$ and CZE, ${ }^{19,20}$ alone and with other drugs. Few analytical procedures were also depicted in the texts for the analysis of REM..$^{21-22}$ UV spectroscopic and HPTLC procedures were reported for the quantification of REM in the solid dosage forms, ${ }^{21}$ whereas LC-MS/MS procedure has been utilized for analysis of REM in the human plasma. ${ }^{22}$ Two stability-indicating liquid chromatographic procedures for the assay of REM from the bulk and formulations were also reported in the literature. ${ }^{23,24}$ Recently, Tammisetty et al..$^{25}$ reported UPLC method and our team has reported RP-HPLC and derivative spectroscopic procedures ${ }^{26,27}$ for the concurrent determination of MET and REM from formulations. The reported UV derivative spectroscopic methods were based on first and $2^{\text {nd }}$ derivative spectroscopic methods, however, the use of higher derivative is preferred for better resolution of interfering analytes, hence in the present work third derivative spectroscopic method was developed. Further, in continuation of our research work on the development of a simple spectroscopic method, ${ }^{28,29}$ three smart and simple UV derivative spectroscopic techniques were reported for the concurrent analysis of MET and REM from formulations.

\section{MATERIALS AND METHODS}

\section{Chemicals and instrument:}

A dual beam UV spectrophotometer (Shimadzu UV-Vis 1700, Tokyo, Japan) was used for recording the UV spectra of solutions by $10 \mathrm{~mm}$ quartz cuvettes using ethanol-water as a solvent. The instrument was adjusted with $2 \mathrm{~nm}$ slit width and medium scanning speed. Recorded spectra were manipulated using UV-probe (Ver. 2.2) software provided with the instrument. To generate smooth manipulated spectra, scanned spectra were smoothened by using $4 \mathrm{~nm}$ wavelength. Active pharmaceutical drugs metformin hydrochloride (purity 98.96\%) and remogliflozin etabonate (purity 99.2\%) were purchased from Bioteck India Limited, Hyderabad, India. Ethanol secured from Sigma Aldrich was an analytical grade. Milli Q (Millipore, USA) was used to prepare the ultra-pure water.

\section{Standard stock and working solutions}

The $25 \mathrm{mg}$ of MET and REM were dissolved separately into two $25 \mathrm{ml}$ calibrated flasks containing $15 \mathrm{ml}$ of water and ethanol respectively. Analytes were dissolved by mixing with sonicator for $10 \mathrm{~min}$ and the final volume was adjusted with respective solvents to get standard stock solutions $(1 \mathrm{mg} / \mathrm{ml})$ of MET and REM. Further, stock solutions were converted into working standard solutions of $100 \mu \mathrm{g} / \mathrm{ml}$ by adding the required amount of water to the aliquot of stock solution.

\section{Preparation sample solutions}

The marketed MET and REM tablets were not accessible in the resident market, hence simulated tablet powder was arranged by adding the required amount of MET, REM and tablet adjuvants (Talc, Hydroxypropyl methylcellulose, magnesium stearate, Primogel, sodium starch glycolate) to get a mixture of MET and REM in a ratio 500:100 and 1000:100. The mixture corresponding to $100 \mathrm{mg}$ of REM, with $500 \mathrm{mg}$ and $1000 \mathrm{mg}$ of MET was transferred separately into $100 \mathrm{ml}$ graduated flasks and solubilized in $50 \mathrm{ml}$ ethanol. Clear solutions were prepared by swirling the solutions for $10 \mathrm{~min}$ and volume was completed with water. Additionally, to bring the amount of both analytes in the linearity range, a sufficient amount of water was added to the aliquot of the sample solution.

\section{Procedure}

\section{Third derivative spectroscopic method (TDS)}

For the construction of calibration curve, seven solutions in the concentration of $2.5,5,10,15,20,25,30 \mu \mathrm{g} / \mathrm{ml}$ of MET and 1, 4, 8, 12, 16, 20, $24 \mu \mathrm{g} / \mathrm{ml}$ of REM were arranged by diluting appropriate volume of working standard solutions separately. UV absorption spectra were recorded for these solutions in the range of $200 \mathrm{~nm}$ to $300 \mathrm{~nm}$ and were saved in the computer. Further, zero-order spectra were changed into $3^{\text {rd }}$ derivative spectra utilizing $4 \mathrm{~nm}$ as $\Delta \lambda$ with ascending factor 100 . 
Then the peak amplitude was determined at $240.1 \mathrm{~nm}$ for MET and a linear curve was generated by plotting a graph against the respective concentration. Similarly, a linear curve was prepared for REM by determining the peak height at $234.8 \mathrm{~nm}$. Regression equations were also generated along with the regression coefficients.

\section{Ratio Second Derivative Spectroscopic method (RSDS)}

Seven aliquots of MET and REM working standard solutions were transferred into $10 \mathrm{ml}$ calibrated flasks, to obtain the amount of MET in the series of 2.5 to $30 \mu \mathrm{g} /$ $\mathrm{ml}(2.5,5,10,15,20,25,30)$ and REM in the range of 1 to $24 \mu \mathrm{g} / \mathrm{ml}(1,4,8,12,16,20,24 \mu \mathrm{g} / \mathrm{ml})$. UV absorption spectra were documented for these solutions in the range of $200 \mathrm{~nm}$ to $300 \mathrm{~nm}$ against dilute ethanol as solvent. Separately, MET and REM solutions comprising of 10 $\mu \mathrm{g} / \mathrm{ml}$ and $20 \mu \mathrm{g} / \mathrm{ml}$ respectively were prepared and scanned. For measurement of MET, ratio spectra of MET were generated by dividing the saved combined spectra of REM and MET by the UV spectrum of REM. Further, these spectra were changed into secondorder derivative spectra employing $4 \mathrm{~nm}$ as $\Delta \lambda$ using an ascending factor of 10 . Then the linearity curve was generated by determining the peak height at $246.6 \mathrm{~nm}$ and plotting the graph against the respective concentration of MET. Similarly, for the measurement of REM, ratio spectra of REM were generated by dividing the REM and MET mixture spectra by the UV spectrum of MET followed by conversion to second derivative spectra. Latter peak height was determined at $277.2 \mathrm{~nm}$ and plotted against the respective concentration of REM. Also, regression equations were generated from both the linearity curves and used for the calculations of the concentration of sample solutions.

\section{Constant Center-Spectrum Subtraction method (CCSS)}

Using the above-recorded ratio spectra of REM the peak height was determined at $248.6 \mathrm{~nm}$ and $277.8 \mathrm{~nm}$ and the difference was calculated. Further, peak height was recorded at $277.8 \mathrm{~nm}$ from the same ratio spectra and the linear graph was plotted between these peak amplitude values to generate a regression equation to identify the constant value. Similarly, from the ratio spectra of MET peak height difference was determined by deducting the peak height at $221.2 \mathrm{~nm}$ from $247.4 \mathrm{~nm}$. Then linear graph was plotted against peak amplitude at $247.4 \mathrm{~nm}$ and a calibration curve was generated. The constant value was deducted from the ratio spectra of REM individually followed by multiplication with UV spectra of $10 \mu \mathrm{g} / \mathrm{ml}$ MET spectra to develop zero-order spectrum of REM. Then the absorption was measured at $\lambda_{\max } 226.2 \mathrm{~nm}$ and a linearity curve was created. Similarly, zero-order spectra of MET were computed and the calibration curve was constructed.

\section{Application of proposed methods to the formulation}

The required amount of sample solution comprising $100 \mathrm{mg}$ REM with $500 \mathrm{mg} / 1000 \mathrm{mg}$ of MET was diluted separately to get the concentration in the range of linearity range. Then the UV spectra were recorded and saved. For the TDS method, the saved zero-order spectra were converted into $3^{\text {rd }}$ order derivative spectra by applying $4 \mathrm{~nm}$ as $\Delta \lambda$ with ascending factor 100 and peak amplitude was determined at $234.1 \mathrm{~nm}$ for REM and $240.1 \mathrm{~nm}$ for MET. For the RSDS method, the above spectra were divided by the UV spectrum of REM $(20 \mu \mathrm{g} / \mathrm{ml})$ and MET $(10 \mu \mathrm{g} / \mathrm{ml})$ separately, to generate ratio spectra of MET and REM respectively. Then these spectra were converted into second derivative spectra using $4 \mathrm{~nm}$ as $\Delta \lambda$ with a scaling factor of 10 . Peak amplitude at $277.2 \mathrm{~nm}$ was measured for REM and at $246.6 \mathrm{~nm}$ for MET. Further, the constant value was deducted from the respective ratio spectra and the resulted spectra were multiplied by UV spectrum of REM $(20 \mu \mathrm{g} / \mathrm{ml})$ and MET $(10 \mu \mathrm{g} / \mathrm{ml})$ separately to generate zero spectra of MET and REM respectively. Absorption was measured at $226.2 \mathrm{~nm}$ from the REM spectrum and $232.9 \mathrm{~nm}$ from the MET spectrum. Finally, concentration was calculated using the respective regression equations.

\section{RESULTS AND DISCUSSION}

UV spectrophotometry is a simple, rapid and reproducible analytical technique used extensively for the quantification of drugs from the formulations. However, quantification of multi-component formulation having overlapping spectra is difficult. Hence, different manipulation of UV spectra has been utilized to analyze the analytes in multicomponent formulations without prior separation. ${ }^{28-31}$ In the present study, the over led

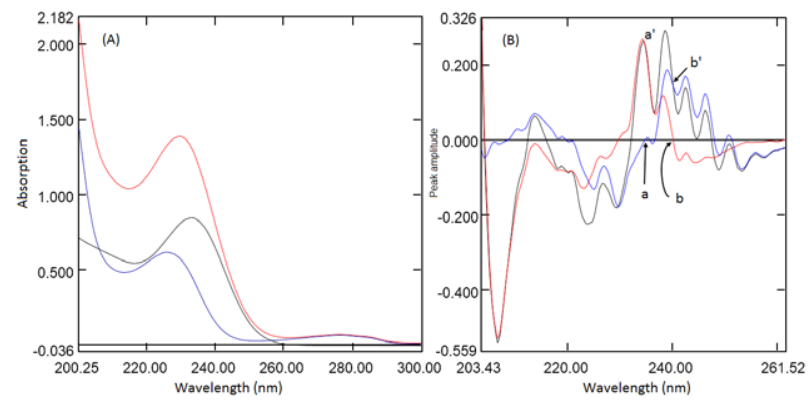

Figure 2: Normal UV spectra of MET, REM and Mixture (A); Third derivative UV spectra of MET, REM and Mixture (B); points "a" and " $b$ " are zero crossings for MET and REM respectively; points a' and b' showing same peak amplitude in pure and mixture. 
UV spectra (Figure 2A) of MET and REM revealed total overlap throughout wavelength of $200 \mathrm{~nm}$ to 300 $\mathrm{nm}$. Hence, derivatization of UV spectra technique was adopted for concurrent analysis of MET and REM from pharmaceutical preparation. Both analytes did not show any absorbance in the range of $300 \mathrm{~nm}-400 \mathrm{~nm}$, hence, the analysis was carried out only in the range of $200 \mathrm{~nm}-300 \mathrm{~nm}$.

\section{Third derivative spectroscopic method (TDA)}

Derivatization of UV spectra method is a simple, perfect and reproducible technique for concurrent determination of multicomponent formulations without prior separation. Further, the use of higher derivatives provides better resolution of overlapping spectra, hence a third derivative spectroscopic was developed. The basic principle involved is a determination of peak height of derivative spectra of one of the components at the zero-crossing point, where the second analyte as well as formulation excipients, will have zero absorbance. Measuring only one analyte without interference from other analytes and excipients. In the present work, zeroorder spectra of REM and MET were converted into third-order derivatives (Figure 2B). Different wavelengths of 2, 4, $8 \mathrm{~nm}$ were studied as $\Delta \lambda$, nevertheless, $4 \mathrm{~nm}$ exhibited superior reproducibility with smooth spectra. REM showed two zero crossings at $292.2 \mathrm{~nm}, 240.1$ $\mathrm{nm}$ and $257.5 \mathrm{~nm}$, at which MET had good absorption, however at $240.1 \mathrm{~nm}$ MET showed high absorption and less intercept. Whereas MET spectra had 4 zero crossing points at 208.0nm, 219.8, 234.8 and $248.2 \mathrm{~nm}$, however at $208 \mathrm{~nm}$ and $219.8 \mathrm{~nm}$ the linearity range was low, whereas at 248.2 the intensity of absorption was low. Further, at $234.8 \mathrm{~nm}$ REM showed good peak amplitude and good correlation. Hence $240.1 \mathrm{~nm}$ and $234.8 \mathrm{~nm}$ were chosen for the further analysis of MET and REM correspondingly. (Figure 3). Further, the third derivative spectra of individual analytes and a mixture of analytes

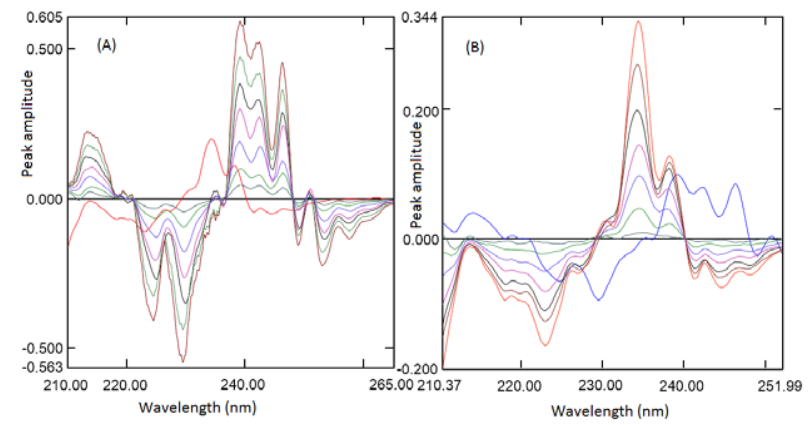

Figure 3: Third derivative UV spectra of $\operatorname{MET}(2.5,5,10,15,20$, 25 and $30 \mu \mathrm{g} / \mathrm{ml}$ with REM (A); Third derivative UV spectra of $\operatorname{REM}(1,4,8,12,16,20$ and $24 \mu \mathrm{g} / \mathrm{ml}$ with MET (B). containing the same amount of analyte showed similar peak amplitude. (Figure 2B)

\section{Ratio Second Derivative Spectroscopic method (RSDS)}

The ratio derivative spectra method has been used to analyze both components from the binary mixture without prior separation. The basic principle of ratio derivative spectroscopic method involves division of UV spectra of a mixture of analytes metformin (M) and remogliflozin $(\mathrm{R})(\mathrm{M}+\mathrm{R})$ with UV spectra of the appropriate concentration of one of the component $\left(R^{\prime}\right)$ to generate a ratio spectra. (Figure 4$)^{27}$ The newly generated ratio spectra of components are presented as equation 1

$$
(\mathrm{M}+\mathrm{R}) / \mathrm{R}^{\prime}=\mathrm{M} / \mathrm{R}^{\prime}+\mathrm{R} / \mathrm{R}^{\prime}
$$

Where $\mathrm{M}$ is metformin and $\mathrm{R}$ is remogliflozin, $\mathrm{R}^{\prime}$ remogliflozin with divisor concentration.

In equation $1, \mathrm{R} / \mathrm{R}^{\prime}$ is constant, this constant can be excluded by transforming the ratio spectra into derivative spectra which showed many maximum and minimum. The peak amplitudes at maximum and minimum are directly proportional to concentration. Further, derivatization removes the effect of other analytes and formulation measuring only one analyte at zero-crossing wavelength of another analyte. In the present work, UV spectra of mixture of MET $(2.5,5,10,15,20,25$ and $30 \mu \mathrm{g} / \mathrm{ml})$ and REM $(1,4,8,12,16,20$ and $24 \mu \mathrm{g} / \mathrm{ml})$ was divided with spectrum of REM $(20 \mu \mathrm{g} / \mathrm{ml})$ for measurement of MET. Different concentration spectra of REM were tried, however, $20 \mu \mathrm{g} / \mathrm{ml}$ showed better recovery. Similarly, for measurement of REM, mixture spectra with increased concentration were divided with MET $(10 \mu \mathrm{g} / \mathrm{ml})$ spectrum. Then the ratio spectra were changed into second derivative spectra with a scaling factor of 10. Different wavelengths of $2 \mathrm{~nm}, 4 \mathrm{~nm}$ and $8 \mathrm{~nm}$ were envisaged as $\Delta \lambda$, nevertheless, $4 \mathrm{~nm}$ displayed better accuracy and smooth spectra. The second derivative
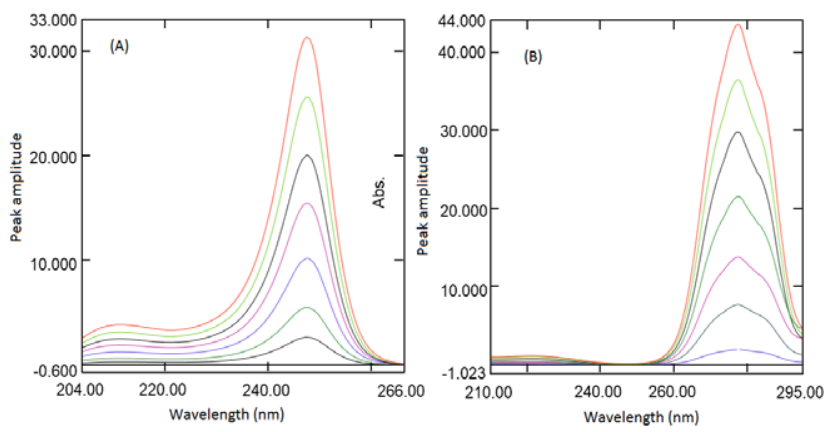

Figure 4: Ratio spectra of MET $(2.5,5,10,15,20,25$ and $30 \mu \mathrm{g} / \mathrm{ml})$ using $20 \mu \mathrm{g} / \mathrm{ml}$ REM spectrum (A); ratio spectra of REM $(1,4$, $8,12,16,20$ and $24 \mu \mathrm{g} / \mathrm{ml}$ ) using $10 \mu \mathrm{g} / \mathrm{ml}$ MET spectrum(B). 
spectra of REM displayed two maximum at $263.2 \mathrm{~nm}$ and $292.1 \mathrm{~nm}$ and three minimum at $270.3 \mathrm{~nm}, 277.2$ $\mathrm{nm}$ and $285.5 \mathrm{~nm}$. The $2^{\text {nd }}$ derivative spectra of MET exhibited two maximum and one minimum at 237.9 $\mathrm{nm}, 253.4 \mathrm{~nm}$ and $246.6 \mathrm{~nm}$ respectively. However, for REM $277.2 \mathrm{~nm}$ and MET $246.6 \mathrm{~nm}$ were selected for the quantification, (Figure 5A) because these are zero crossings for one analyte where another analyte had good absorption. Further, ratio second derivative spectra of a mixture of both analytes and spectra of individual pure analytes consisting of the same amount of analytes showed similar peak amplitude (Figure 5B).

\section{Constant centered-Spectrum subtraction method (CCSS)}

The constant centered subtraction method involves the conversion of spectra of a mixture of two analytes into individual zero-order spectra and measurement of absorption at their $\lambda_{\text {max }}$ wavelength. This can be achieved by the following steps, namely determination of constant by amplitude difference and its subtraction followed by multiplication. For the present study, from the aboveobtained ratio spectra, peak amplitude was computed at two different wavelengths $(\lambda 1$ and $\lambda 2)$, subtraction of peak amplitude from one another will cancel the constant $\left(\mathrm{R} / \mathrm{R}^{\prime}\right)$ according to the below equation 2;

$\mathrm{P}_{1}-\mathrm{P}_{2}=\left(\mathrm{M} / \mathrm{R}^{\prime}\right)_{1}+$ Constant $-\left[\left(\mathrm{M} / \mathrm{R}^{\prime}\right)_{2}+\right.$ Constant $]$

Which can be further simplified to

$$
\mathrm{P}_{1}-\mathrm{P}_{2}=\left(\mathrm{M} / \mathrm{R}^{\prime}\right)_{1}-\left(\mathrm{M} / \mathrm{R}^{\prime}\right)_{2}
$$

Where $\mathrm{P}_{1}$ and $\mathrm{P}_{2}$ are peak amplitude of spectra at $\lambda_{1}$ and $\lambda_{2}$ correspondingly.

In the present work, the two wavelengths selected were $248.6 \mathrm{~nm}$ and $277.8 \mathrm{~nm}$ for REM; $221.2 \mathrm{~nm}$ and 247.4 $\mathrm{nm}$ for MET.

Further, a linearity curve was built by plotting a graph between the peak height difference of ratio spectra of
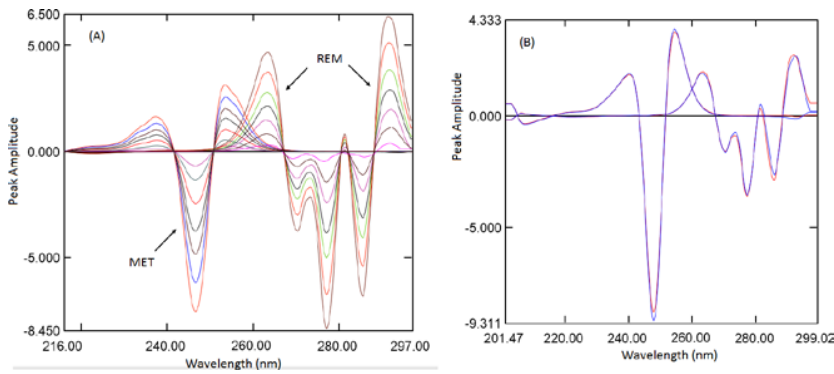

Figure 5: Ratio second derivative spectra of $\operatorname{MET}(2.5,5,10$, $15,20,25$ and $30 \mu \mathrm{g} / \mathrm{ml}$ ) Ratio second derivative spectra of $\operatorname{REM}(1,4,8,12,16,20$ and $24 \mu \mathrm{g} / \mathrm{ml})(A)$ and Ratio second derivative spectra of pure and mixture showing same peak amplitude (B).
$\mathrm{M}$ against peak height of ratio spectra at one of the selected wavelengths (277.8 nm for REM and $247.4 \mathrm{~nm}$ for MET). The generated regression equation (3) can be used to calculate the hypothesized $\left(\mathrm{M} / \mathrm{R}^{\prime}\right)_{1}$, hence

$$
\begin{gathered}
\left(\mathrm{M} / \mathrm{R}^{\prime}\right) 1-\left(\mathrm{M} / \mathrm{R}^{\prime}\right) 2=\operatorname{slope}\left(\mathrm{M} / \mathrm{R}^{\prime}\right) 1+\text { intercept } \\
\Delta \mathrm{P}=\operatorname{slope} \mathrm{P}_{\text {hypothesized }}+\text { intercept } \\
\Delta \mathrm{P}_{\mathrm{MET}}=1.144 \mathrm{x}-0.0333(\text { Supplementary file } \mathrm{S} 1) \\
\left.\Delta \mathrm{P}_{\mathrm{REM}}=1.1151 \mathrm{x}-0.0793 \text { (Supplementary file } \mathrm{S} 1\right)
\end{gathered}
$$

Further, the constant $\mathrm{R} / \mathrm{R}^{\prime}$ can be computed by subtracting the hypothesized $\mathrm{P}$ value from the noted peak height of mixture at the identical wavelength, this represents only $\mathrm{R} / \mathrm{R}$ ' as per the below equation (4)

$$
\begin{array}{r}
R / R^{\prime}=\left[M / R^{\prime}+R / R^{\prime}\right]_{1}-\left(M / R^{\prime}\right)_{1} \\
C . V=P_{\text {measured }}-P_{\text {hypothesized }}
\end{array}
$$

\section{Remogliflozin}

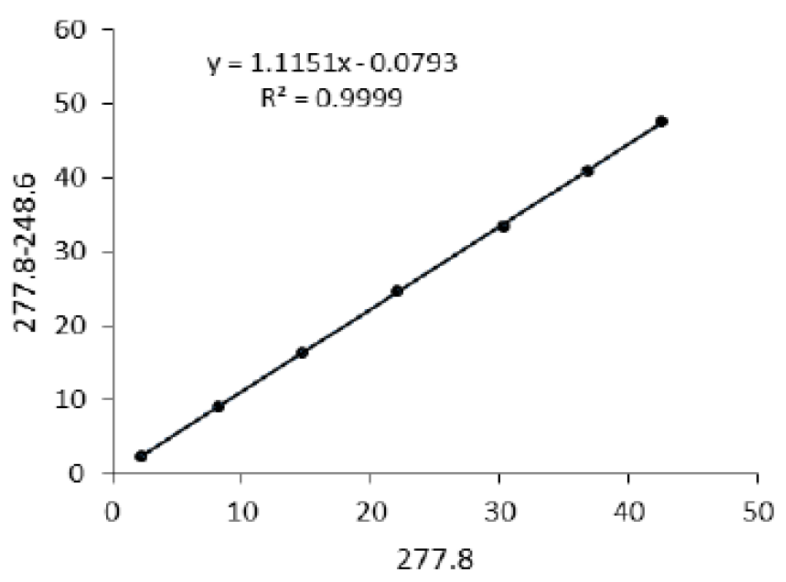

\section{Metformin}

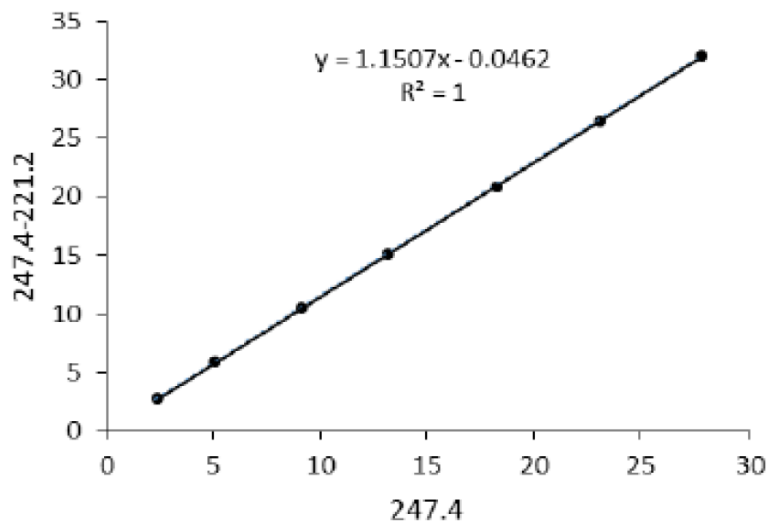

Supplementary file S1: Calibration curves for MET and REM developed by a peak height difference of ratio spectra against peak height of ratio spectra at one of the selected wavelengths. 
Where C.V is R/R' (constant value), $\mathrm{P}_{\text {measured }}$ is the peak amplitude determined from the ratio spectra of the mixture at $221.2 \mathrm{~nm}$ and $\mathrm{P}_{\text {hypothesized }}$ is calculated amplitude value from the specified regression equation at the same wavelength.

Further, the obtained constant value (R/R') was subtracted from the ratio spectra as per equation 5, followed by multiplication with the spectrum of $R$ (equation 6) used for creating the ratio spectra, which will give zero-order spectra of $\mathrm{M}$ (Equation 7, Figure 6A). Further, the regression equation was extracted from the linearity curve plotted by measuring the absorbance of the zero-order spectrum of $\mathrm{M}$ at its $\lambda_{\max }(232.9 \mathrm{~nm})$ against the corresponding concentration of $\mathrm{M}$.

$$
\begin{gathered}
(\mathrm{M}+\mathrm{R}) / \mathrm{R}^{\prime}=\mathrm{M} / \mathrm{R}^{\prime}+\mathrm{R} / \mathrm{R}^{\prime}-\mathrm{R} / \mathrm{R}^{\prime} \\
(\mathrm{M}+\mathrm{R}) / \mathrm{R}^{\prime}=\mathrm{M} / \mathrm{R}^{\prime} * \mathrm{R}^{\prime} \\
(\mathrm{M}+\mathrm{R}) / \mathrm{R}^{\prime}=\mathrm{M}
\end{gathered}
$$

Similarly, zero-order spectra of R (Figure 6B) was generated, by subtracting the constant value followed by multiplication with the spectrum of $M$ used for
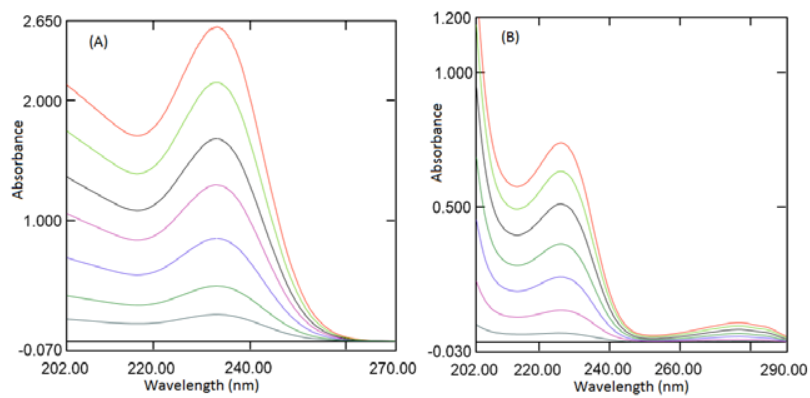

Figure 6: Zero order spectra of $\operatorname{MET}(2.5,5,10,15,20,25$ and $30 \mu \mathrm{g} / \mathrm{ml}$ ) generated after multiplication with $20 \mu \mathrm{g} / \mathrm{ml}$ REM spectrum (A); zero order spectra of REM $(1,4,8,12,16,20$ and $24 \mu \mathrm{g} / \mathrm{ml}$ ) generated after multiplication $10 \mu \mathrm{g} / \mathrm{ml}$ MET spectrum(B).

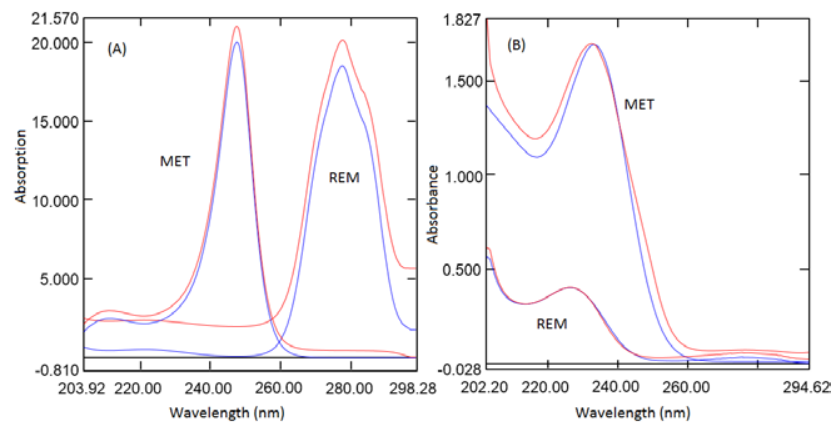

Figure 7: Ratio spectra of MET and REM of pure and mixture (A); zero-order spectra of pure (Blue) and mixture (Red) of MET and REM generated after multiplication showing same absorbance (B). creating the ratio spectra of $\mathrm{R}$ and calibration curve was constructed by mearing absorbance at its $\lambda_{\max }(226.2 \mathrm{~nm})$ against the corresponding concentration of R. Further, ratio spectra (Figure 7A) and zero-order spectra (Figure $7 \mathrm{~B})$ generated from a mixture of analytes and the pure analytes consisting of same amount analytes showed similar absorbance (Figure 7).

\section{Method validation}

The proposed UV derivative spectroscopic techniques were validated for various ICH parameters such as linearity range, the limit of detection and limit of quantification, accuracy, precision and stability. ${ }^{32}$

\section{Linearity, $L O D$ and $L O Q$}

Seven solutions of MET (2.5, 5, 10, 15, 20, 25, $30 \mu \mathrm{g} /$ $\mathrm{ml})$ and $\operatorname{REM}(1,4,8,12,16,20$ and $24 \mu \mathrm{g} / \mathrm{ml})$ were analyzed in triplicate. MET showed linearity in the range of 2.5 to $30 \mu \mathrm{g} / \mathrm{ml}$ and REM in the range of 1 to $24 \mu \mathrm{g} / \mathrm{ml}$ with an excellent correlation coefficient $\left(\mathrm{r}^{2}\right.$ $>0.998$ ) by all three methods. (Supplementary file S2) The experiments were performed as per the abovementioned procedure, then the calibration curves were
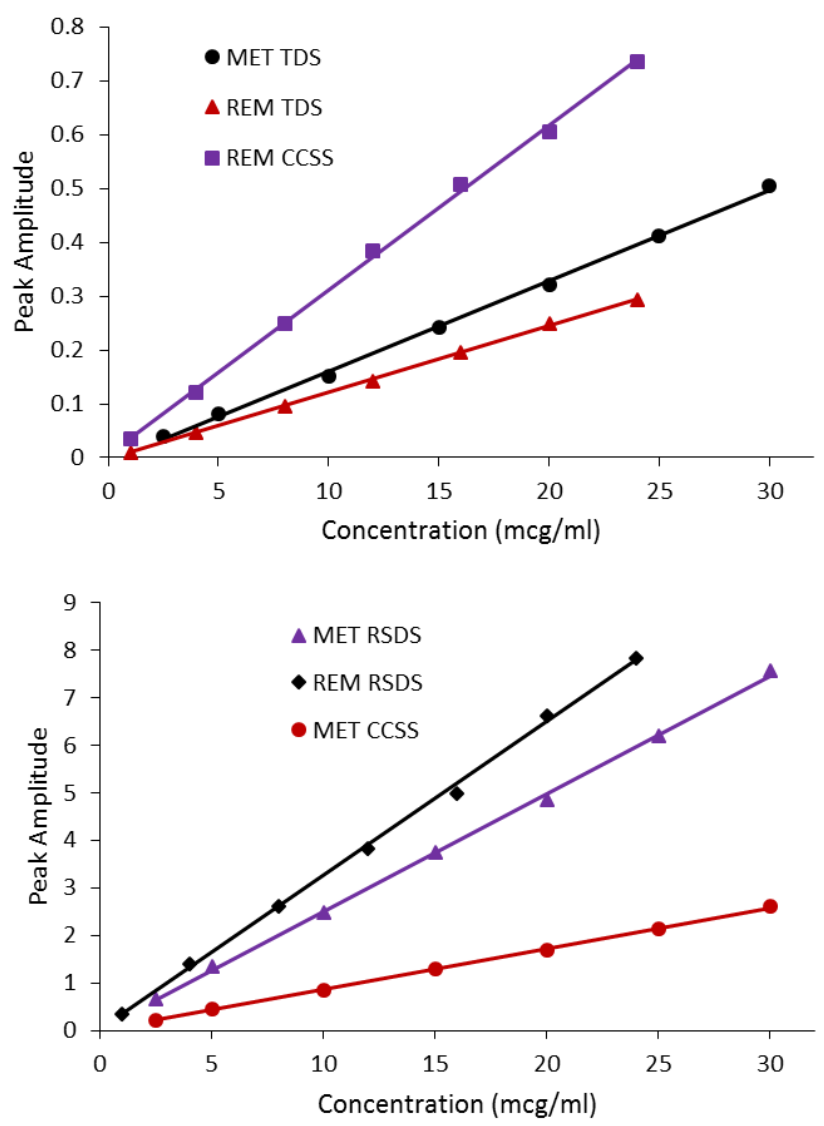

Supplementary File S2: Calibration curves for MET and REM by all three methods. 
generated and the corresponding regression equations were generated. (Table 1).

Limit of detection and limit of quantification were computed using the corresponding equations $3.3 \mathrm{~d} / \mathrm{s}$ and $10 \mathrm{~d} / \mathrm{s}$. Where $d$ is the standard deviation of the response and $s$ is the slope of the calibration curve. The calculated LOD and LOQ values are tabulated in Table 1.

\section{Precision}

The precision of the methods was determined as inter day and intraday precision by investigating both analytes at three different concentration (low, medium and high) to cover the entire linearity range. Intraday precision was performed by analyzing three concentrations of REM and MET, in triplicate on the first day, further, for the inter-day these solutions were assessed for three successive days by all three methods. The precision was presented as percent relative standard deviation and presented in Table 2. The low \% RSD found by all three methods indicated the precision of the developed techniques.

\section{Accuracy and specificity}

\begin{tabular}{|c|c|c|c|c|c|c|}
\hline \multirow{2}{*}{$\begin{array}{c}\text { Parameters } \\
\text { Drugs }\end{array}$} & \multicolumn{2}{|c|}{$\begin{array}{l}\text { Third Derivative Absorbance } \\
\text { method }\end{array}$} & \multicolumn{2}{|c|}{$\begin{array}{l}\text { Ratio Second Derivative } \\
\text { method }\end{array}$} & \multicolumn{2}{|c|}{$\begin{array}{l}\text { Constant Center Subtraction } \\
\text { method }\end{array}$} \\
\hline & REM & MET & REM & MET & REM & MET \\
\hline Wave length [nm] & 234.8 & 240.1 & 277.2 & 246.6 & 226.2 & 232.9 \\
\hline Linearity Range $[\mu \mathrm{g} / \mathrm{ml}]$ & $1-24$ & $2.5-30$ & $1-24$ & $2.5-30$ & $1-24$ & $2.5-30$ \\
\hline LOD $[\mu \mathrm{g} / \mathrm{ml}]$ & 0.31 & 0.76 & 0.23 & 0.69 & 0.28 & 0.81 \\
\hline $\mathrm{LOQ}[\mu \mathrm{g} / \mathrm{ml}]$ & 0.94 & 2.18 & 0.74 & 1.96 & 0.83 & 2.42 \\
\hline Slop [m] & 0.0124 & 0.0168 & 0.3232 & 0.2471 & 0.0305 & 0.0856 \\
\hline Intercept [c] & -0.0031 & -0.0076 & 0.0252 & 0.0407 & 0.0066 & 0.0076 \\
\hline Correlation Coefficient $\left[r^{2}\right]$ & 0.9993 & 0.9985 & 0.9983 & 0.9992 & 0.9987 & 0.9994 \\
\hline
\end{tabular}

\begin{tabular}{|c|c|c|c|c|c|c|c|}
\hline & \multirow[b]{2}{*}{$\begin{array}{c}\text { Amount of } \\
\text { Drug }[\mu \mathrm{g} / \mathrm{mL}]\end{array}$} & \multicolumn{3}{|c|}{ Inter-day } & \multicolumn{3}{|c|}{ Intra-day } \\
\hline & & $\begin{array}{l}\text { Amount found } \\
\text { Mean }[n=3] \pm S D\end{array}$ & \%RSD & $\% R E$ & $\begin{array}{c}\text { Amount found } \\
\text { Mean }[n=9] \pm S D\end{array}$ & $\%$ RSD & $\%$ RE \\
\hline \multicolumn{8}{|c|}{ Third Derivative Absorbance method } \\
\hline \multirow{3}{*}{ REM } & 1.00 & $0.98 \pm 0.01$ & 1.02 & -2.00 & $1.01 \pm 0.01$ & 0.99 & 1.00 \\
\hline & 12.00 & $11.89 \pm 0.12$ & 1.01 & -0.92 & $12.06 \pm 0.08$ & 0.66 & 0.50 \\
\hline & 24.00 & $23.87 \pm 0.29$ & 1.21 & -0.54 & $23.81 \pm 0.15$ & 0.63 & -0.79 \\
\hline \multirow{3}{*}{ MET } & 2.50 & $2.52 \pm 0.04$ & 1.59 & 0.80 & $2.49 \pm 0.04$ & 1.61 & -0.40 \\
\hline & 15.00 & $14.81 \pm 0.09$ & 0.61 & -1.27 & $14.77 \pm 0.18$ & 1.22 & -1.53 \\
\hline & 30.00 & $29.74 \pm 0.42$ & 1.41 & -0.87 & $30.15 \pm 0.32$ & 1.06 & 0.50 \\
\hline \multicolumn{8}{|c|}{ Ratio Second Derivative Spectroscopic method } \\
\hline \multirow{3}{*}{ REM } & 1.00 & $1.01 \pm 0.02$ & 1.98 & 1.00 & $0.99 \pm 0.01$ & 1.01 & -1.00 \\
\hline & 12.00 & $11.79 \pm 0.16$ & 1.36 & -1.75 & $11.81 \pm 0.09$ & 0.76 & -1.58 \\
\hline & 24.00 & $23.68 \pm 0.22$ & 0.93 & -1.33 & $23.78 \pm 0.22$ & 0.93 & -0.92 \\
\hline \multirow{3}{*}{ MET } & 2.50 & $2.46 \pm 0.03$ & 1.22 & -1.60 & $2.51 \pm 0.02$ & 0.80 & 0.40 \\
\hline & 15.00 & $14.88 \pm 0.17$ & 1.14 & -0.80 & $14.73 \pm 0.19$ & 1.29 & -1.80 \\
\hline & 30.00 & $29.79 \pm 0.38$ & 1.28 & -0.70 & $29.57 \pm 0.42$ & 1.42 & -1.43 \\
\hline \multicolumn{8}{|c|}{ Constant Center Spectrum Substation method } \\
\hline \multirow{3}{*}{ REM } & 1.00 & $0.99 \pm 0.01$ & 1.01 & -1.00 & $1.01 \pm 0.01$ & 0.99 & 1.00 \\
\hline & 12.00 & $12.06 \pm 0.11$ & 0.91 & 0.50 & $11.81 \pm 0.13$ & 1.10 & -1.58 \\
\hline & 24.00 & $23.85 \pm 0.25$ & 1.05 & -0.62 & $23.66 \pm 0.29$ & 1.23 & -1.42 \\
\hline \multirow{3}{*}{ MET } & 2.50 & $2.46 \pm 0.01$ & 0.41 & -1.60 & $2.49 \pm 0.04$ & 1.61 & -0.40 \\
\hline & 15.00 & $14.88 \pm 0.2$ & 1.34 & -0.80 & $14.83 \pm 0.23$ & 1.55 & -1.13 \\
\hline & 30.00 & $29.55 \pm 0.41$ & 1.39 & -1.50 & $29.63 \pm 0.34$ & 1.15 & -1.23 \\
\hline
\end{tabular}


Accuracy of the projected procedures was assessed by the standard addition method and represented as percent recovery and percent relative error. To determine the percent recovery a known amount of standard solutions of REM and MET at three levels (50\%, 100\% and $150 \%$ ) were transferred to an earlier evaluated sample. These solutions were investigated by proposed methods by following the above-described procedures and the concentration of each analyte by each method was calculated by using corresponding regression equations. The experiments were performed in triplicate and the mean percentage recovery (Table 3) was found to be from $99.08 \%$ to $100.15 \%$ for MET and from $98.73 \%$ to $100.27 \%$ for REM by all three methods. The low $\%$ RE (Table 2) also showed the acceptable accuracy of the proposed techniques. Further, the good percentage recovery of added analytes to the formulation showed

\begin{tabular}{|c|c|c|c|c|}
\hline \multirow{4}{*}{ Table 3: Recovery study results. } \\
\hline \multirow{4}{*}{$\begin{array}{c}\text { Amount added } \\
{[\mu \mathrm{g} / \mathrm{ml}]}\end{array}$} & \multicolumn{3}{c|}{ \% Recovery } \\
\cline { 2 - 5 } & 1 & 100.89 & 98.57 & 101.25 \\
\hline \multirow{4}{*}{ REM } & 2 & 98.97 & 99.15 & 100.44 \\
\cline { 2 - 5 } & 3 & 100.28 & 98.46 & 99.12 \\
\cline { 2 - 5 } & Across Mean & 100.05 & 98.73 & 100.27 \\
\cline { 2 - 5 } & $\%$ RSD & 0.98 & 0.37 & 1.08 \\
\hline \multirow{4}{*}{ MET } & 5 & 98.82 & 99.79 & 100.67 \\
\cline { 2 - 5 } & 10 & 100.24 & 101.58 & 98.29 \\
\cline { 2 - 5 } & 15 & 98.19 & 99.08 & 99.48 \\
\cline { 2 - 5 } & Across Mean & 99.08 & 100.15 & 99.48 \\
\cline { 2 - 5 } & \%RSD & 1.05 & 1.29 & 1.19 \\
\hline
\end{tabular}

a an amount added to the previously analyzed sample (REM $2 \mu \mathrm{g} / \mathrm{ml}$ and $\operatorname{MET} 10 \mu \mathrm{g} / \mathrm{ml}$ ) no interference from the tablet excipients, indicated the specificity of the methods.

\section{Stability studies}

Stability studies were performed in terms of benchtop for $24 \mathrm{hr}$ at room temperature and refrigerated sample for 7 days. No change in the assay results was observed even after $24 \mathrm{hr}$ (short term) and 7 days (long term) indicating the stability of analytes in the experimental and refrigerated conditions respectively.

\section{Application of proposed methods to formulations}

The recommended UV derivative spectroscopic techniques were applied for the concurrent determination of REM and MET from the solid dosage form (Table 4). The mean percentage recovery was found to be from $99.77 \%$ to $101.83 \%$ for REM and $98.41 \%$ to $99.85 \%$ for MET and it is in agreement with the amount of analytes in the formulations. Further, the suggested techniques were statistically compared to the reported HPLC method ${ }^{26}$ concerning accuracy and precision. No significant discrepancy was witnessed in the assay outcomes acquired by the suggested UV derivative techniques and reported HPLC method. The students' $t$-test and F values were also lower than the critical values.

\section{CONCLUSION}

Three simple, accurate and reproducible UV derivative analytical techniques were established for the concurrent quantification of REM and MET from the pharmaceutical preparations. Proposed methods are ecofriendly and economical because dilute-ethanol was used as a solvent, no sophisticated instrument was required and software supplied with the UV

Table 4: Formulation Assay results and statistical results of REM and MET by proposed and reference methods.

\begin{tabular}{|c|c|c|c|c|c|c|c|c|}
\hline & \multicolumn{4}{|c|}{ Remogliflozin (\%recovery) } & \multicolumn{4}{|c|}{ Metformin (\%recovery) } \\
\hline & $\begin{array}{c}\text { Ref } \\
\text { method }^{c}\end{array}$ & TDA & RSDS & ccss & $\begin{array}{c}\text { Ref } \\
\text { method }^{c}\end{array}$ & TDA & RSDS & ccss \\
\hline REM:MET 100:1000 & 100.67 & 99.26 & 101.05 & 98.78 & 100.24 & 98.65 & 99.06 & 98.55 \\
\hline REM:MET 100:500 & 99.19 & 98.20 & 98.93 & 100.32 & 98.48 & 99.72 & 100.83 & 99.07 \\
\hline Mean $^{\mathrm{a}}$ & 100.04 & 99.77 & 99.94 & 101.83 & 100.00 & 99.12 & 98.41 & 99.85 \\
\hline S.D & 1.28 & 1.07 & 1.09 & 1.14 & 0.80 & 0.98 & 1.12 & 1.07 \\
\hline$N$ & 6.00 & 6.00 & 6.00 & 6.00 & 6.00 & 6.00 & 6.00 & 6.00 \\
\hline Variance & 1.64 & 1.14 & 1.18 & 1.30 & 1.42 & 0.95 & 1.27 & 1.14 \\
\hline \multicolumn{2}{|c|}{ Student's t test $(2.22)^{b}$} & 0.39 & 0.13 & 0.29 & & 1.39 & 0.88 & 0.22 \\
\hline \multicolumn{2}{|l|}{$F(5.05)^{b}$} & 1.43 & 1.38 & 1.26 & & 1.49 & 1.12 & 1.24 \\
\hline
\end{tabular}

${ }^{a}$ mean of six determinations; ${ }^{b}$ critical vales at $p=0.05$; SD : standard deviation; ${ }^{c}$ Reference method: ${ }^{26}$ Chromolith ( $50 \mathrm{~mm} \times 4.6 \mathrm{~mm}$ i.d. $5 \mu \mathrm{m}$ ) $\mathrm{C}_{18}$ column, Mobile phase acetonitrile and mixture of $25 \mathrm{mM}$ sodium dodecyl sulfate, $10 \mathrm{mM}$ potassium dihydrogen phosphate $(\mathrm{pH} 3.5)$ in a ratio of $42 \%: 58 \%(\mathrm{v} / \mathrm{v})$ respectively, $2 \mathrm{ml} / \mathrm{min}$ flow rate, at $230 \mathrm{~nm}$. 
spectrophotometer has been used for processing of scanned UV spectra. Very simple manipulation techniques such as ratio derivative and third derivative spectroscopic methods were applied for the concurrent determination of REM and MET without the prior separation. Excellent recovery from the formulation with low $\%$ RSD and \% RE indicated no intervention from the tablet adjuvants. Further, suggested procedures are simple and rapid, hence could be utilized for quality control of MET and REM formulation.

\section{ACKNOWLEDGEMENT}

The authors are thankful to the Deanship of Scientific Research, King Faisal University, Al-Ahsa, Saudi Arabia for financial support under the annual project (Grant \#170117).

\section{CONFLICT OF INTEREST}

The authors declare no conflict of interest.

\section{ABBREVIATIONS}

REM: Remogliflozin Etabonate; MET: Metformin Hydrochloride; UV: Ultraviolet; \%RE: Percentage Relative Error; \%RSD: Percent Relative Standard Deviation; ICH: International Conference on Harmonisation; HPLC: High-performance liquid chromatography; UPLC: Ultra high performance liquid chromatography; LOD: Limit of detection; LOQ: Limit of quantification.

\section{REFERENCES}

1. Rena G, Hardie DG, Pearson ER. The mechanisms of action of metformin. Diabetologia. 2017;60(9):1577-85.

2. Jabbour S, Ziring B. Advantages of extended-release metformin in patients with type 2 diabetes mellitus. Postgrad Med. 2011;123(1):15-23.

3. Rojas LBA, Gomes MB. Metformin: An old but still the best treatment for type 2 diabetes. Diabetol Metab Syndr. 2013;5(1):6.

4. Simes BC, MacGregor GG. Sodium-Glucose Cotransporter-2 (SGLT2) Inhibitors: A Clinician's Guide. Diabetes Metab Syndr Obes. 2019;12:2125-36.

5. Scheen AJ. Pharmacodynamics, efficacy and safety of sodium-glucose co-transporter type 2 (SGLT2) inhibitors for the treatment of type 2 diabetes mellitus. Drugs. 2015;75(1):33-59.

6. Donnan K, Segar L. SGLT2 inhibitors and metformin: Dual antihyperglycemic therapy and the risk of metabolic acidosis in type 2 diabetes. Eur J Pharmacol. 2019;846:23-9.

7. Hussey EK, Kapur A, O'Connor-Semmes R, Tao W, Rafferty B, Polli JW, et al. Safety, pharmacokinetics and pharmacodynamics of remogliflozin etabonate, a novel SGLT2 inhibitor and metformin when co-administered in subjects with type 2 diabetes mellitus. BMC Pharmacol Toxico. 2013;14(1):25.

8. Fujimori Y, Katsuno K, Nakashima I, Ishikawa-Takemura Y, Fujikura H, Isaji M. Remogliflozin etabonate, in a novel category of selective low-affinity sodium glucose cotransporter (SGLT2) inhibitors, exhibits antidiabetic efficacy in rodent models.J Pharmacol Exp Ther. 2008;327(1):268-76.

9. Dharmalingam $\mathrm{M}$, Aravind $\mathrm{SR}$, Thacker $\mathrm{H}$, et al. Efficacy and safety of Remogliflozin Etabonate, a new sodium glucose co-transporter-2 inhibitor, in patients with type 2 diabetes mellitus: A 24-week, randomized, double-blind, active-controlled trial. Drugs. 2020;11:1-4.

10. Zelniker TA, Wiviott SD, Raz I, Im K, Goodrich E, Bonaca MP. SGLT2 inhibitors for primary and secondary prevention of cardiovascular and renal outcomes in type 2 diabetes: A systematic review and meta-analysis of cardiovascular outcome trials. Lancet. 2019;393(10166):31-9.

11. Khalid WS, Al-Janabi MAK, Luaibi HM. Determination of the Dissociation Constants of Metformin from a Second Derivative UV Spectrum. Int J Res Pharm Sci 2020;11(1):790-6.

12. Majithia RH, Khodadiya A, Patel VB. Spectrophotometric method development and validation for simultaneous estimation of Anagliptin and Metformin $\mathrm{HCl} B Y \mathrm{Q}$ - Absorption ratio method in synthetic mixture. Heliyon. 2020;6(5):e03855.

13. Attimarad MV, Nair AB, Aldhubaib BE. Development of liquid chromatographic method for the simultaneous determination of metformin and miglitol in human plasma: Application to pharmacokinetic studies. J Iranian Chem Soc. 2015;12(9):1629-36.

14. Gurav SB, Bhatia NM. Development and Validation of Novel StabilityIndicating LC Method for the Determination of Saxagliptin and Metformin. Indian J Pharmaceut Edu Res. 2020;54(2s):s350-7.

15. Sebaiy MM, El-Adl SM, Baraka MM, Hassan AA. Rapid RP-HPLC method for simultaneous estimation of metformin, pioglitazone and glimepiride in human plasma. Acta Chromatogr. 2020;32(1):16-21.

16. Munde MK, Kulkarni NS, Sen AK, Sen DB. A Novel Validated Stability Indicating Analytical Method for Simultaneous Quantification of Metformin Hydrochloride and Empagliflozin in Bulk and Marketed Formulation by HPTLC using Box-Wilson Experimental Design Approach. Indian J Pharmaceut Edu Res . 2020;54(3s):s644-56.

17. Chaudhari K, Wang J, Xu Y, Winters A, Wang L, Dong X, et al. Determination of metformin bio-distribution by LC-MS/MS in mice treated with a clinically relevant paradigm. PLoS One. 2020;15(6):e0234571.

18. Mohammed BHAA, Akhtar JS, Keddal GL, Mufarreh A, Jessica W, Sami DE. Development and Validation of LC-MS/MS Method for Simultaneous Determination of Metformin and Four Gliptins in Human Plasma. Chromatographia. 2017;80(6):891-9.

19. Attimarad M. Multivariate optimization of a capillary zone electrophoresis assay method for simultaneous quantification of metformin and vildagliptin from a formulation. J Liq Chrom Relat Tech. 2016;39(8):401-7.

20. Alnajjar AO, Idris AM, Attimarad MV, Elgorashe REE. Quadruple Response Factorial Design Optimization of Capillary Zone Electrophoresis Assay Procedure for Metformin and Sitagliptin Combination. J Liq Chrom Relat Tech. 2015;38(14):1379-83.

21. Tayade AB, Patil AS, Shirkhedkar AA. Development and Validation of Zero Order UV-Spectrophotometric Method by Area Under Curve Technique and High Performance Thin Layer Chromatography for the Estimation of Remogliflozin Etabonate in Bulk and In-House Tablets. Inventi Rapid: Pharm Anal Qual Assu. 2019;3:1-5.

22. Sigafoos JF, Bowers GD, Castellino S, Culp AG, Wagner DS, Reese MJ, et al. Assessment of the drug interaction risk for remogliflozin etabonate, a sodiumdependent glucose cotransporter-2 inhibitor: Evidence from in vitro, human mass balance and ketoconazole interaction studies. Drug Metab Dispos. 2012;40(11):2090-101.

23. Bhatkar T, Badkhal AV, Bhajipale NS. Stability Indicating RP-HPLC Method Development and Validation for the Estimation of Remogliflozin Etabonate in Bulk and Pharmaceutical Dosage Form. Int J Pharmace Res. 2020;12(4).

24. Shah DA, Gondalia II, Patel VB, Mahajan A, Chhalotiya UK. Stability indicating liquid chromatographic method for the estimation of remogliflozin etabonate. J Chem Metrol. 2020;14(2):125-32.

25. Tammisetty M, Challa BR, Puttagunta SB. A novel analytical method for the simultaneous estimation of remogliflozin and metformin hydrochloride by UPLC/PDA in bulk and formulation. Application to the estimation of product traces. Turk J Pharm Sci. 2020;39699.

26. Attimarad M, Elgorashe REE, Subramaniam R, Islam MM, Venugopala KN, Nagaraja S, et al. Development and Validation of Rapid RP-HPLC and Green Second-Derivative UV Spectroscopic Methods for Simultaneous Quantification of Metformin and Remogliflozin in Formulation using Experimental Design. Separations. 2020;7(4):59. 
27. Attimarad M, Nair AB, Sreeharsha N, Al-Dhubiab BE, Venugopala KN, Shinu P. Development and Validation of Green UV Derivative Spectrophotometric Methods for Simultaneous Determination Metformin and Remogliflozin from Formulation: Evaluation of Greenness. Int J Environ Res Public Health. 2021;18(2):448.

28. Chohan MS, Elgorashe REE, Balgoname AA, Attimarad M, SreeHarsha N, Venugopala $\mathrm{KN}$, et al. Eco-friendly Derivative UV Spectrophotometric Methods for Simultaneous Determination of Diclofenac Sodium and Moxifloxacin in Laboratory Mixed Ophthalmic Preparation. Indian J Pharm Edu Res. 2019;53(4):166-74.

29. Attimarad M, Chohan MS, Balgoname AA. Simultaneous Determination of Moxifloxacin and Flavoxate by RP-HPLC and Ecofriendly Derivative
Spectrophotometry Methods in Formulations. Int J Environ Res Public Health 2019;16(7):1196.

30. Kamal AH, El-Malla SF, Hammad SF. A Review on UV spectrophotometric methods for simultaneous multicomponent analysis. Eur J Pharm Med Res. 2016;3(2):348-60.

31. Salinas F, Nevado JJB, Mansilla AE. A new spectrophotometric method for quantitative multicomponent analysis resolution of mixtures of salicylic and salicyluric acids. Talanta. 1990;37(3):347-51.

32. ICH Harmonized Tripartite Guideline; Text on Validation of Analytical Procedures, Text and Methodology, Q2 (R1), International Conference on Harmonization; ICH Secretariat, c/o IFPMA, 30 rue de St-Jean: Geneva, Switzerland. 2005;1-17.

\section{PICTORIAL ABSTRACT}
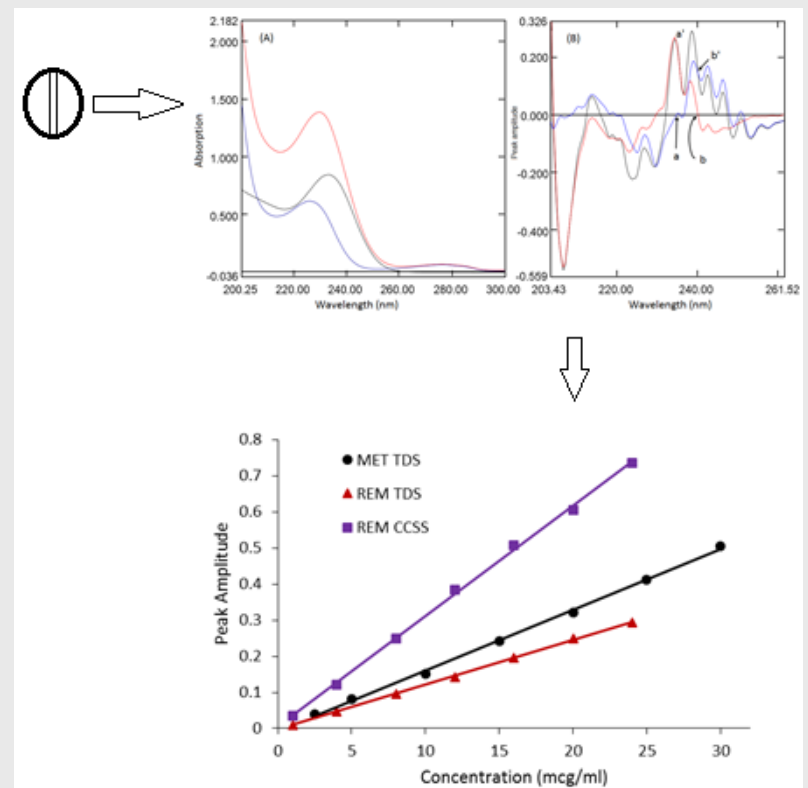

\section{SUMMARY}

Three smart, reproducible and non-sophisticated UV derivative spectroscopic procedures were established for the concurrent determination of metformin and remogliflozin by manipulation of UV spectra. Validation of proposed techniques exhibited linearity in the concentration of 2.5 to $30 \mu \mathrm{g} / \mathrm{ml}$ and 1 to 24 $\mu \mathrm{g} / \mathrm{ml}$ for MET and REM correspondingly by all three methods. The average percentage of recovery showed was in the range of $99.08 \%$ to $100.15 \%$ for MET and $98.73 \%$ to $100.27 \%$ for REM. Further, both analytes were quantified from the formulation using proposed spectroscopic methods with high accuracy. Compression of all three methods with the reported HPLC method showed no variations in the assay results. Hence the suggested techniques could be utilized for regular quality control of formulation consisting of MET and REM.

\section{About Authors}

Dr. Mahesh Attimarad, holds Master of Pharmacy (Al-Ameen College of Pharmacy) and Ph.D in Pharmaceutical Chemistry (Rajiv Gandhi University of Health Sciences, Bangalore, India). He is presently working at College of Clinical Pharmacy, King Faisal University, Saudi Arabia and involved in teaching Pharmaceutical Organic, Analytical and Medicinal Chemistry at under graduate and post graduate levels. He is actively involved in the research and received several research grants from KFU. His major research interests include development of new analytical methods for drug molecules for estimation in pharmaceutical formulations and body fluids, Microwave assisted synthesis of organic compounds, Design and synthesis of NSAIDs and Screening for anti-inflammatory and analgesic activities. He was awarded second position in the outstanding researcher Award, King Faisal University, Saudi Arabia during 2019. He has more than 100 national and international publications in peer reviewed journals to his credit.

Cite this article: Attimarad M, Nair AB, Nagaraja S, Aldhubiab BE, Venugopala KN, Pottathil S. Smart UV Derivative Spectrophotometric Methods for Simultaneous Determination of Metformin and Remogliflozin: Development, Validation and Application to the Formulation. Indian J of Pharmaceutical Education and Research. $2021 ; 55(1 s): s 293-s 302$. 